\title{
Biogenic larvicidal formulation of metabolites from Steinernema saimkayi symbiont Xenorhabdus stockiae KUT6 against dengue vector Aedes aegypti
}

\author{
Jissin, M. ${ }^{1}$ and Vani, C..$^{*}$ \\ Department of Biotechnology, Karunya Institute of Technology and Sciences, Coimbatore, Tamil Nadu, India \\ *Corresponding author e-mail: vani@karunya.edu \\ Received 29 June 2019; received in revised form 27 March 2020; accepted 27 March 2020
}

\begin{abstract}
To characterize the production and larvicidal activity of Xenorhabdus stockiae KUT6 Petroleum ether extracts from Luria Broth and induced Quorum sensing medium containing N-3- oxododecanoyl Homoserine Lactone inducer against dengue vector Aedes aegypti. The Galleria mellonella larvae were reared for the isolation of Steinernema saimkayi symbiont Xenorhabdus stockiae KUT6 from Cucumber field soil sample in NBTA. Then for the extraction of compounds the KUT6 strains were cultured in Luria Broth and Quorum Sensing optimized media using N-3-oxododecanoyl homoserine lactone inducer. The larvicidal activity of Xenorhabdus stockiae KUT6 of petroleum ether extracts were bioassayed against $4^{\text {th }}$ instar Aedes aegypti dengue vector. The maximum rate of mortality were recorded of the samples A-24h, B-48h, C-72h, A1-24h, B1-48h, C1-72h at different concentrations $50 \mu \mathrm{g} / \mathrm{ml}$, $100 \mathrm{\mu g} / \mathrm{ml}$ and $150 \mu \mathrm{g} / \mathrm{ml}$ respectively for $24 \mathrm{~h}$ to $72 \mathrm{~h}$ of exposure treatment. The morphological characteristics of Xenorhabdus stockiae KUT6 in NBTA were red core colonies with blue background surrounded by zone of inhibition. After $24 \mathrm{~h}$ exposure maximum rate of $100 \%$ mortality of Aedes aegypti $4^{\text {th }}$ instar larvae was attained when treated with sample C1-72h 50 $\mu \mathrm{g} / \mathrm{ml}$ of the petroleum ether extracts of quorum sensed medium whereas the sample $\mathrm{C} 72 \mathrm{~h}$ petroleum ether extracts of KUT6 cultured in Luria broth recorded 100\% mortality at $150 \mu \mathrm{g}$ on $24 \mathrm{~h}$ exposure indicates enhancement in the product yield. The study assures the use of Xenorhabdus stockiae KUT6 petroleum ether extracts as biocontrol agent could be beneficial for the control of dengue vectors.
\end{abstract}

\section{INTRODUCTION}

Research on microorganisms exists in symbiotic relationship with entomopathogenic nematodes are gaining much attention in these years emphasizing secured effects as biocontrol agents for sustainable environment (Chamaiporn et al., 2017). This knowledge has contributed furnished hypothesis to our research on microorganism and its secondary metabolites on larvicidal activity against dengue vector Aedes aegypti. Foregoing research towards interpretation of specific interactions of microorganisms interlinking Integrated Pest Management environment friendly against dengue vector is paramount for its control. The spatial distribution of dengue vectors, Aedes aegypti and Aedes albopictus are affected by climatic factors (Yukiko, 2011). Tremendous researches proved the relation of dengue virus and its vectors Aedes aegypti and Aedes albopictus for their involvement in dengue transmission (Yukiko, 2011). Uncontrolled urbanization and global warming in developed countries exert an impact on vector mosquitoes causing vector-borne diseases (Goh et al., 1985). Controlling vectors reduces its susceptibility to transmit dengue fever.

The primary vector Aedes aegypti is the vector mosquito responsible for dengue fever and dengue hemorrhagic fever. Dengue is the most common arthropod-borne viral infection 
caused by dengue virus (DENV) a positive single stranded, positive sense enveloped RNA virus of Flaviviridae family and are mainly transmitted by Aedes aegypti and Aedes albopictus. Infection with any of the four dengue virus serotypes (DENV 1,2,3,4) leads to inapparent infection syndrome to classic dengue fever (DF), DHF and DSS with vascular leakage and shock (Mustafa et al., 2015). According to National Vector Borne Disease Control Programme (NVBDCP) report published in 2018 around 40886 cases in India including 2175 cases in Tamil Nadu alone dengue fever has been reported statistically (National Vector Borne Disease Control Programme 2018). According to WHO continuous usage of chemical insecticides such as synthetic pyrethroids, malathion and carbamates may results decreased susceptibility towards vector target (WHO, 2016). But the major disadvantage is that it can harm non-target beings in the environment and continuous usage of chemical insecticides causes health related issues and develops negative impact of resistance among mosquitoes (Guedes et $a l ., 2014)$. Since no vaccines are available there is a need for developing eco-friendly biodegradable, low cost biological insecticides for the eradication.

The continuous usage of chemicals over a long period of time induces mosquito population resistance (Kovendan et al., 2011). The biocontrol agents with Integrated Vector management used for the control involves Bacillus thuringiensis israelensis or Bacillus sphaericus and their toxins, Xenorhabdus/Photorhabdus species, Metarhizium anisopliae and Beauveria bassiana, Acanthamoeba polyphaga and the copepod Macrocyclops albidus are commonly used (Park, 2015; Setha et al., 2016).

Xenorhabdus species are entomopathogenic bacteria symbiotically associated with insect parasitic nematodes of the family Steinernematidae. The entomopathogenic nematodes are obligate or facultative parasites of insects having soft and nonsegmented body (Dilipkumar et al., 2017).
Reseach reviewed several gram negative bacteria communicates through synthesising and secreting small diffusible inducer homoserine lactone signal molecules by a special mechanism called Quorum sensing (Harshad et al., 2014). Since quorum sensing is also associated towards bacterial growth; bacterial compounds can intercept and modulates their virulence factor that enhances the pathogenicity (Chan et al., 2011; Lade et al., 2014). The future perspective of the existence of Acyl Homoserine Lactone-mediated QS in Gram negative bacteria and its potential role can be used as an alternative approach for the product yield formulation (Bhardwaj et al., 2012). In the present study inspired by the natural phenomena of entomopathogenic symbiotic bacteria we evaluated the larvicidal activity of crude extracts against Aedes aegypti $4^{\text {th }}$ instar larvae from isolated Xenorhabdus species.

\section{MATERIALS AND METHODS}

Collection of soil samples for the isolation of Entomopathogenic Nematode by Insect Baiting Technique

Ten different agricultural field soil sample namely Tomato, Ginger, Cucumber, Turmeric, Coconut, Banana,Yam, Tapioca, Sugar Cane and Pumpkin were collected from the depth of at least $15 \mathrm{~cm}$ (Vitta et al., 2017). Visual debris were removed from the collected soil samples to avoid saprobic contamination. To the 10 different soil sample container, five Galleria mellonella larvae were inoculated for baiting with particular nematodes. The containers were covered with black cloths to aid the infection at $25-28^{\circ} \mathrm{C}$. The soil samples infected with Gallerial larvae were observed for up to 7 days and the cadaver infected with the nematode appeared black color indicating the presence of Steinernema species were rinsed thoroughly in sterile water (Boszormenyi et al., 2009). 


\section{Isolation of Xenorhabdus species}

From the infected Galleria mellonella, hemolymph were taken and streaked on Nutrient agar Bromothymolblue 2,3,5Triphenyltetrazolium chloride medium for incubation at $27^{\circ} \mathrm{C}$ for $24 \mathrm{~h}$. Bioluminiscent colonies observed under UV light at $365 \mathrm{~nm}$ and further cultured to establish pure isolates in Luria broth and stored at $4^{\circ} \mathrm{C}$ (San-Blas et al., 2017). The isolated bacteria were subjected to 16SrRNA sequencing.

\section{Identification of Xenorhabdus species}

The symbiotic bacterial isolates were represented as KUT6 (Karunya University Thadiyoor) based on the location of the soil samples and its symbiont entomopathogenic nematode as KUT1 which was confirmed by morphological (staining and motility) and cultural (NBTA medium) characterization methods. The 16SrRNA was done for species level identification of KUT6 strain.

\section{Induction of Quorum sensing using N 3- Oxododecanoyl Homoserine Lactone}

To enhance its product yield a loopful of culture was inoculated into $3000 \mathrm{ml}$ of Luria broth with N 3-Oxododecanoyl homoserine lactone inducer and kept in rotary shaker incubator at $120 \mathrm{rpm}$ for 24-72h. Aliquotes of culture broth were separated every $24 \mathrm{~h}$ and centrifuged at $10000 \mathrm{rpm}$ for $20 \mathrm{~min}$ (Hinchliffe et al., 2010; Harshad et al., 2014).

\section{Extraction of secondary metabolites}

Culture supernatant of Xenorhabdus stockiae KUT6 strain in Luria broth and Quorum sensing Luria broth medium at $24 \mathrm{~h}, 48 \mathrm{~h}$ and $72 \mathrm{~h}$ were extracted with equal volume of the solvent such as petroleum ether, chloroform, ethyl acetate and butanol. The solvent fraction of petroleum ether was evaporated at $60^{\circ} \mathrm{C}$ at $100 \mathrm{rpm}$ and the residue was stored at $4^{\circ} \mathrm{C}$ for further analysis (Hinchliffe et al., 2010).

\section{Rearing of Aedes aegypti $4^{\text {th }}$ Instar Larvae}

The Aedes aegypti were collected from Centre for Research in Medical Entomology, Madurai, Tamil Nadu, India. At Laboratory condition the Aedes aegypti egg rafts were kept in tray containing tap water. An adequate amount of sterilized yeast powder and dog biscuit were added to the tray in the ratio of 4:1 ratio to enhance the growth of larvae. For the Bioassay $4^{\text {th }}$ instar larvae of Aedes aegypti were used.

Larvicidal activity of secondary metabolites from Luria broth media and optimized media against Aedes aegypti The extracts obtained from petroleum ether of Luria broth Xenorhabdus stockiae KUT6 culture supernatant and modified Luria broth with inducer were analyzed in different concentrations against $4^{\text {th }}$ instar larvae of Aedes aegypti. From the stock standard of $1 \mathrm{mg} / \mathrm{ml}$ extracts with the concentration of $50 \mu \mathrm{g} / \mathrm{ml}, 100 \mu \mathrm{g} / \mathrm{ml}$ and $150 \mu \mathrm{g} / \mathrm{ml}$ were added into the disposable cup containing $20 \mathrm{ml}$ of chlorine free tap water and $104^{\text {th }}$ instar larvae of Aedes aegypti per cup were added in the bioassay cups in triplicates. The petroleum ether solvent without the extracts were kept as control. The rate of mortality was calculated from 24 to $72 \mathrm{~h}$ duration using Abbott's formula (Padmanabhan et al., 2005; Abbot, 1925). All the experiments were carried out in Department of Biotechnology, Karunya University, Coimbatore.

Corrected Mortality $=$ Observed mortality Control Mortality/100 - Control Mortality x $100 \%$

\section{Statistical analysis}

Statistical analysis was performed with graphed prism 6 software using one-way analysis of variance. The $\mathrm{LC}_{50}$ values were calculated using probit analysis (Guedes et al., 2014).

\section{Histopathology}

For the histopathological studies treated and untreated Aedes aegypti IV ${ }^{\text {th }}$ instar larvae were stored in $10 \%$ formalin solution. The material was cut with glass knives in a rotary microtome and fixed with hematoxylin-eosin blue, which is used to study the morphological changes using phase contrast microscope and are compared with the control sample (Sugumar et al., 2014). 


\section{RESULTS}

Isolation and screening of Xenorhabdus species associated entomopathogenic nematodes

Based on the hypothetical research, from the cucumber soil sample the black dead nematode infected Galleria mellonella were collected (Fig. 1A and 1B). The Gallerial hemolymph were inoculated in Nutrient Bromothymolblue 2,3,5 Triphenyltetrazolium chloride Agar medium, the bacterial culture showed blue green background inhibit zone at $365 \mathrm{~nm}$ in the UV light. The morphological appearance of the isolated bacterial strain were, red coloured colonies with blue background inhibit zone, swamming and smooth free phase 1 colonies (Fig. 2A). The phase 2 colonies were appeared as dark red colonies.
The phenotypic characterization of the bacterial strain recorded as swamming motility, and in Gram staining it was observed gram negative small rod shaped organism. Maximum growth was recorded at $27-30^{\circ} \mathrm{C}$ dark conditions for 24-48 hrs. The primary confirmed phase I colonies were given for $16 \mathrm{~S}$ r RNA sequenicng. The 16SrRNA sequence of Xenorhabdus stockiae KUT6 strain has been submitted with NCBI (Accession Number- MF125441) (Fig. 3).

\section{Induced Quorum sensing media and extraction of metabolites}

The product yields of the compounds were induced by inoculating $24 \mathrm{~h}$ culture in Luria broth containing N 3- Oxododecanoyl homoserine lactone QS inducer. After centrifugation out of the four solvents; the active secondary metabolites from Luria

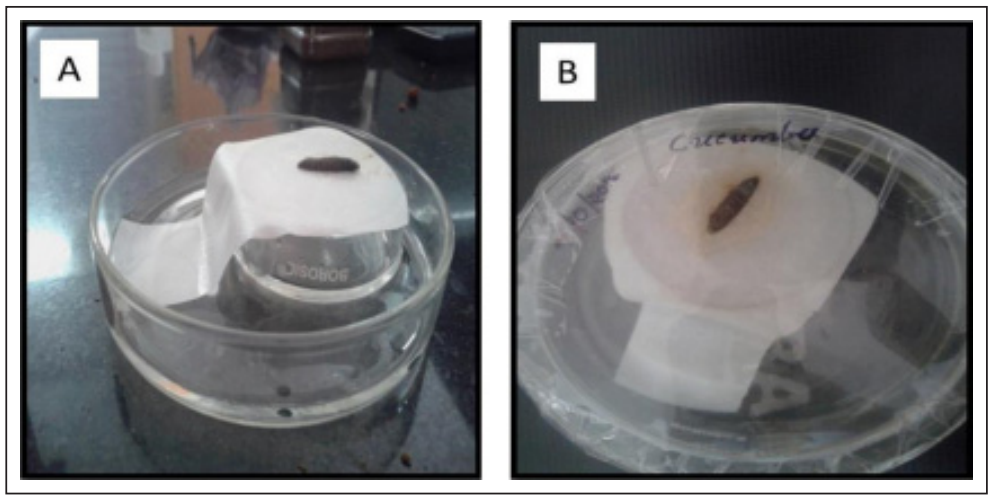

Figure 1. The entomopathogenic nematode infected black dead Galleria mellonella from cucumber field soil.

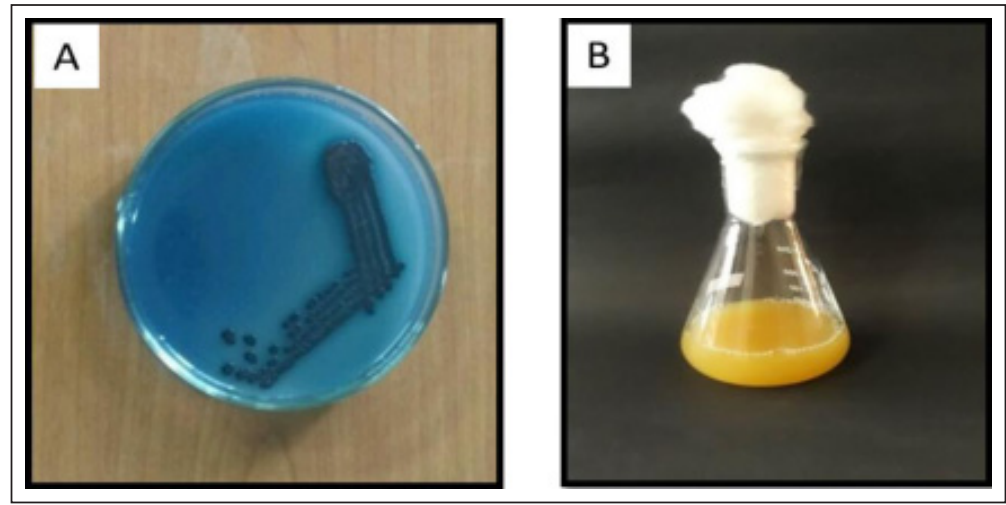

Figure 2a. Red core colonies with blue background on NBTA Medium. Fig. 2b. Xenorhabdus species grown in Luria Broth. 


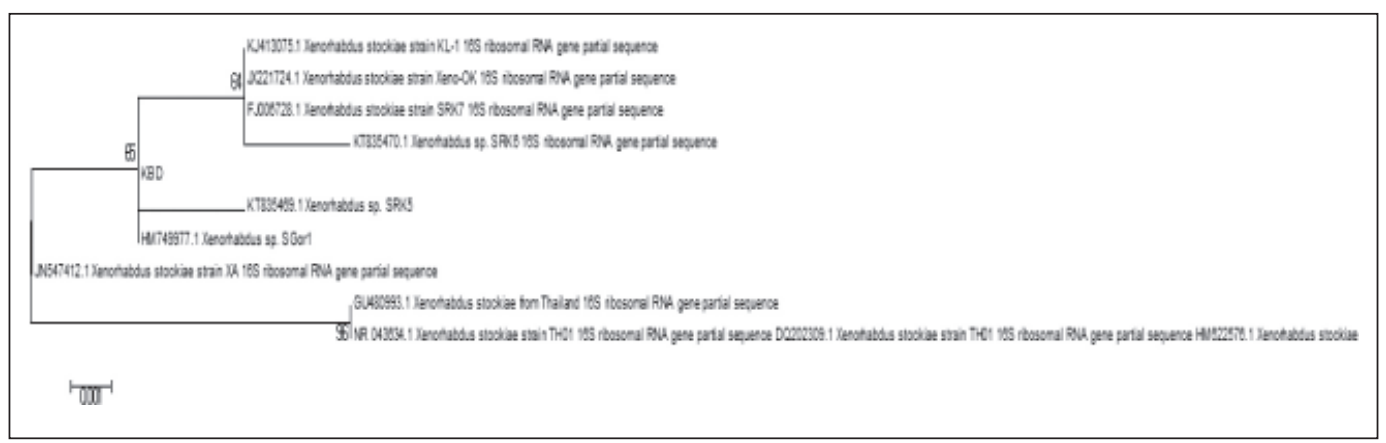

Figure 3. Maximum likelihood tree data of Xenorhabdus stockiae isolated from soil entomopathogenic nematodes. Bootstrap values $>50 \%$ are displayed and the sequences obtained in this study are named as KUT6, reference sequence names are given followed by the GenBank Accession Number.
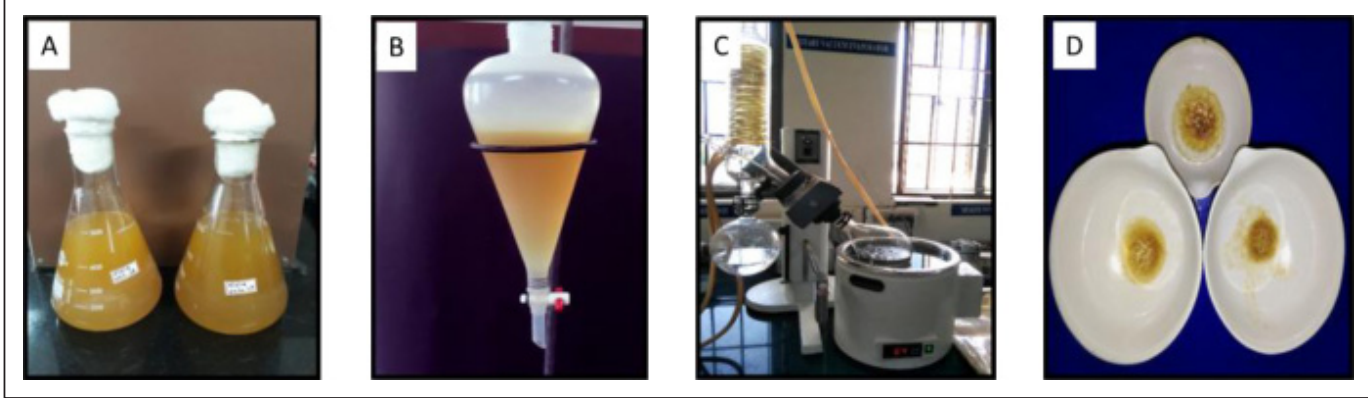

Figure 4a. The Xenorhabdus stockiae KUT6 were inoculated in Luria Broth for samples A (24h), B (48h) and $\mathrm{C}(72 \mathrm{~h})$ and are incubated at $28^{\circ} \mathrm{C} \mathrm{N} 3$ - oxododecanoyl homoserine lactone quorum sensing inducer in Luria broth were prepared and incubated for samples A1 (24h), B1 (48h) and C1 (72h); Fig. 4b After centrifugation the secondary metabolites were extracted in Petroleum Ether; Fig. 4c The active compunds formed crystal structure and stored.

Table 1. The petroleum ether secondary metabolites from Xenorhabdus stockiae KUT6 strain in Luria Broth were weighed and calculated

\begin{tabular}{cccc}
\hline Incubation time $(\mathrm{hr})$ & Empty weight $(\mathrm{g})$ & Dry weight $(\mathrm{g})$ & Weight of compound $(\mathrm{g})$ \\
\hline A (24) & 1.202 & 1.409 & 0.207 \\
B (48) & 1.202 & 1.335 & 0.133 \\
C (72) & 1.202 & 1.292 & 0.0903 \\
\hline
\end{tabular}

Table 2. The petroleum ether secondary metabolites from Xenorhabdus stockiae KUT6 strain in QS induced Luria Broth medium were weighed and calculated

\begin{tabular}{cccc}
\hline Incubation time $(\mathrm{hr})$ & Empty weight $(\mathrm{g})$ & Dry weight $(\mathrm{g})$ & Weight of compound $(\mathrm{g})$ \\
\hline A1 (24) & 24.438 & 24.645 & 0.207 \\
B1 (48) & 74.646 & 75.002 & 0.356 \\
C1 (72) & 74.646 & 73.646 & 1.000 \\
\hline
\end{tabular}

broth (Fig. 2B) and modified medium were found in petroleum ether (Fig. 4A, 4B and $4 \mathrm{C})$. The wet weight and dry weight of the petroleum ether extracts were given below (Table 1, 2). 


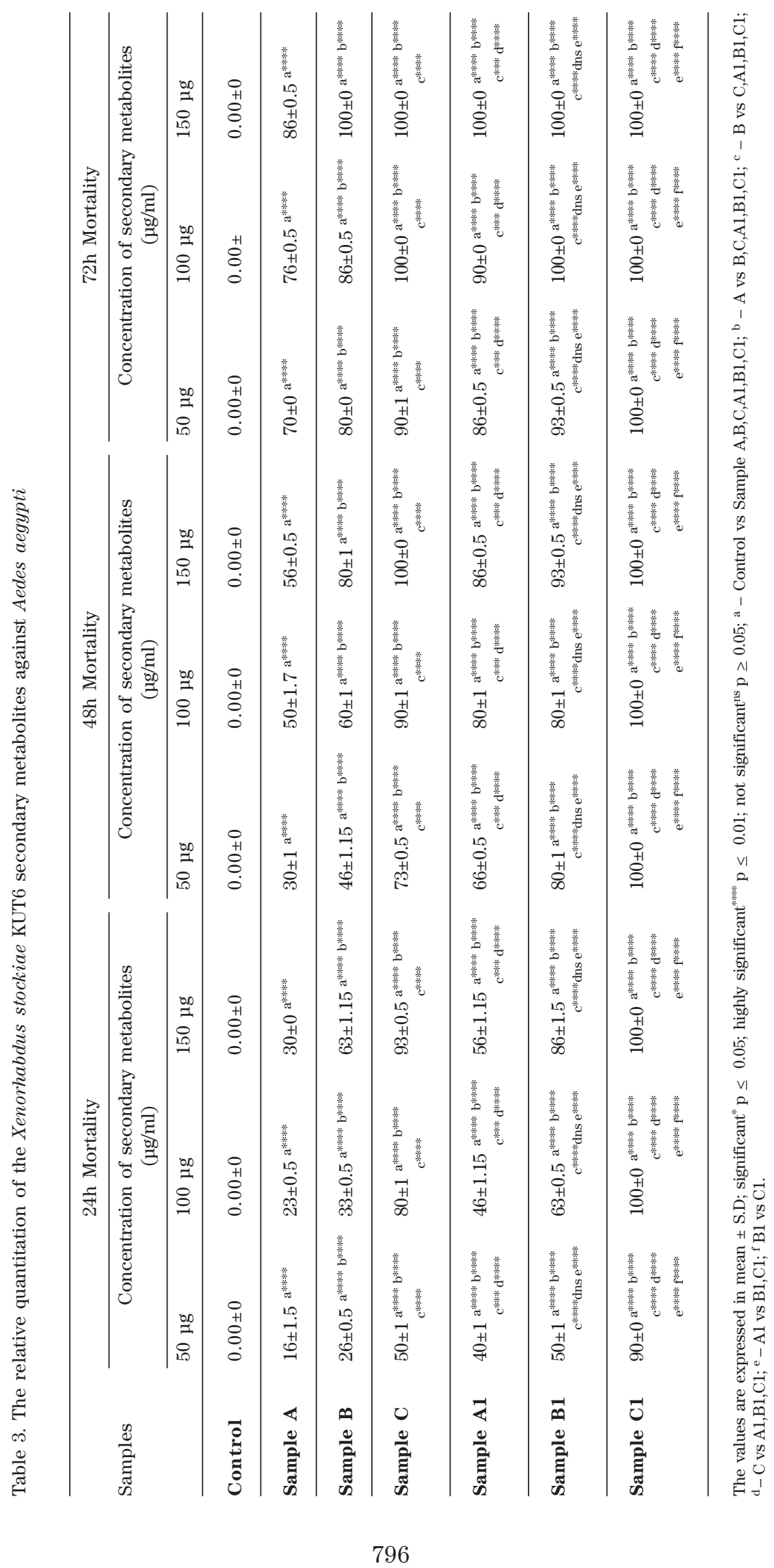


Larvicidal activity of petroleum ether extracts against Aedes aegypti

Larvicidal activity of the secondary metabolite against $4^{\text {th }}$ instar larvae of Aedes aegypti was recorded for $24 \mathrm{~h}, 48 \mathrm{~h}$ and 72h exposure (Fig. 5A and 5B) (Table 3). In Control bioassay cup no dead larvae were obtained. On 24h exposure, Petroleum Ether extracts of Sample A (24h) showed $16.6 \%$ mortality at $50 \mu \mathrm{g} / \mathrm{ml} ; 23.3 \%$ mortality at 100 $\mu \mathrm{g} / \mathrm{ml}$ and $23.3 \%$ mortality at $150 \mu \mathrm{g} / \mathrm{ml}$. On $48 \mathrm{~h}$ exposure, petroleum ether extract of Sample A (24h) showed $30 \%$ at $50 \mu \mathrm{g} / \mathrm{ml}$; $50 \%$ mortality at $100 \mu \mathrm{g} / \mathrm{ml}$ and $76.6 \%$ at 150 $\mu \mathrm{g} / \mathrm{ml}$. On $72 \mathrm{~h}$ exposure in vitro, recorded $23.3 \%$ mortality at $50 \mu \mathrm{g} / \mathrm{ml} ; 50 \%$ mortality at $100 \mu \mathrm{g} / \mathrm{ml}$ and $86.6 \%$ mortality at 150 $\mu \mathrm{g} / \mathrm{ml}$ (Fig. 6A).
Larvicidal activity of extracts of Sample B (48h) showed $26.6 \%$ mortality at $50 \mu \mathrm{g} / \mathrm{ml}$; $30 \%$ at $100 \mu \mathrm{g} / \mathrm{ml}$ and $53.3 \%$ mortality at $150 \mathrm{\mu g} / \mathrm{ml}$ on $24 \mathrm{~h}$ exposure. $48 \mathrm{~h}$ exposure recorded $46.6 \%$ mortality at $50 \mu \mathrm{g} / \mathrm{ml} ; 50 \%$ mortality at $100 \mu \mathrm{g} / \mathrm{ml}$ and $70 \%$ mortality at $150 \mathrm{\mu g} / \mathrm{ml}$. On the $72 \mathrm{~h}$ expsoure Sample B (48h) extracts showed $70 \%$ mortality at 50 $\mu \mathrm{g} / \mathrm{ml} ; 76.6 \%$ at $100 \mu \mathrm{g} / \mathrm{ml}$ and $100 \%$ at 150 $\mathrm{gg} / \mathrm{ml}$ (Fig. 6B). Sample C (72h) petroleum ether extracts of $24 \mathrm{~h}$ exposure showed $36.6 \%$ at $50 \mu \mathrm{g} / \mathrm{ml} ; 66.6 \%$ mortality at $100 \mu \mathrm{g} / \mathrm{ml}$ and $66.6 \%$ mortality at $150 \mu \mathrm{g} / \mathrm{ml}$. On the $2^{\text {nd }}$ day of exposure the percentage of mortality was $46.6 \%$ at $50 \mu \mathrm{g} / \mathrm{ml} ; 86.6 \%$ at $100 \mu \mathrm{g} / \mathrm{ml}$ and $86.6 \%$ mortality at $150 \mathrm{\mu g} / \mathrm{ml}$. On $72 \mathrm{~h}$ treatment $86.6 \%$ mortality at $50 \mu \mathrm{g} / \mathrm{ml} ; 100 \%$ mortality was recorded at $100 \mu \mathrm{g} / \mathrm{ml}$ and $150 \mu \mathrm{g} / \mathrm{ml}$ concentrations (Fig. 6C).

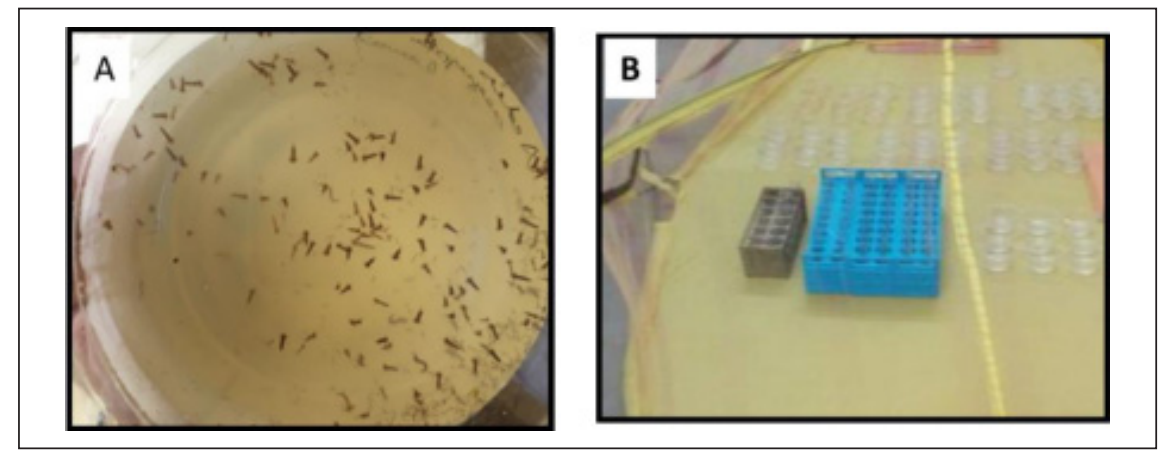

Figure 5a. The $4^{\text {th }}$ instar larvae of Aedes aegypti hatched from the egg were inoculated in chlorine free tap water; Fig. 5b The Biolarvicidal activity of seconadary metabolites from Xenorhabdus stokiae KUT6 were performed under 24-72h exposure treatment.

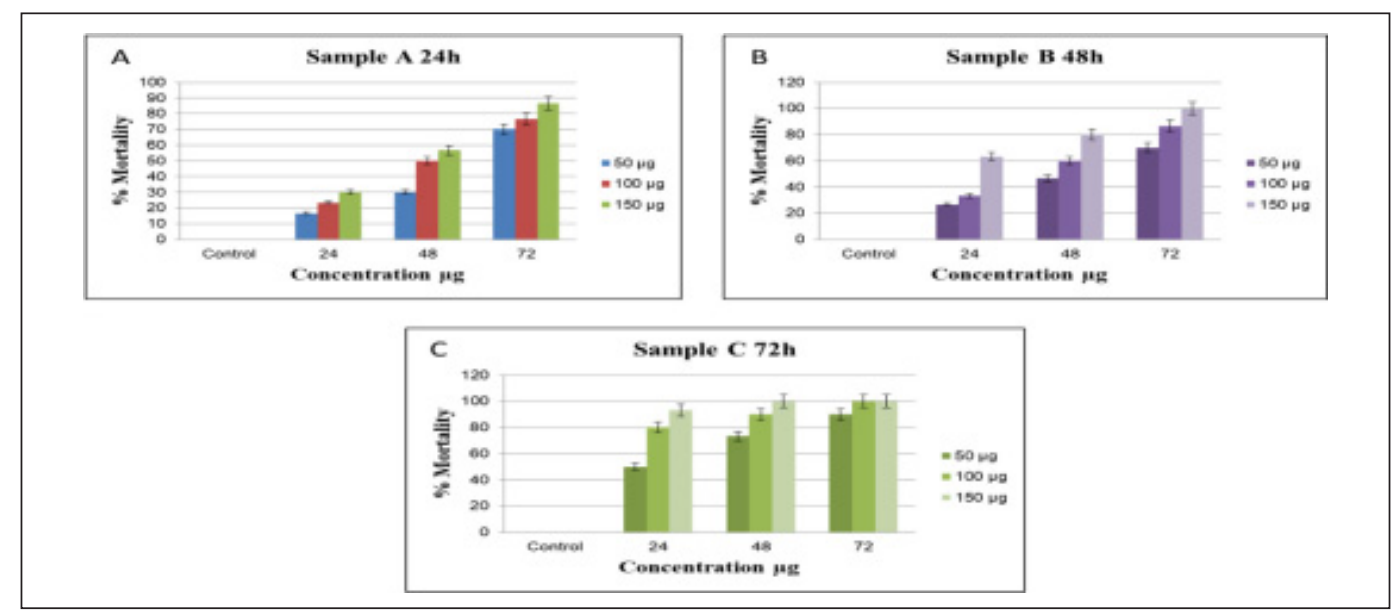

Figure 6a. Larvicidal Activity of Sample A 24h; Fig. 6b Larvicidal Activity of Sample B 48h; Fig. 6c Larvicidal Activity of Sample C 72h against Aedes aegypti. 
QS Sample A1 (24h) extracts showed $33.3 \%$ moratlity at $50 \mu \mathrm{g} / \mathrm{ml} ; 36.6 \%$ at 100 $\mu \mathrm{g} / \mathrm{ml}$ and $36.6 \%$ mortality rate at $150 \mu \mathrm{g} / \mathrm{ml}$ on the $24 \mathrm{~h}$ treatment. The $48 \mathrm{~h}$ exposure of the larvicidal activity was $53.3 \%$ at $50 \mu \mathrm{g} / \mathrm{ml}$ and $100 \mu \mathrm{g} / \mathrm{ml}$ and $56.6 \%$ at $150 \mu \mathrm{g} / \mathrm{ml}$. On the $3^{\text {rd }}$ day of exposure $83.3 \%$ mortality was recorded at $50 \mu \mathrm{g} / \mathrm{ml} ; 90 \%$ at $100 \mu \mathrm{g} / \mathrm{ml}$ and maximum mortality 100\% was attained at $150 \mathrm{\mu g} / \mathrm{ml}$ (Fig. 7A).

QS Sample B1 (48h) extracts on $24 \mathrm{~h}$ showed $40 \%$ at $50 \mu \mathrm{g} / \mathrm{ml} ; 50 \%$ at $100 \mu \mathrm{g} / \mathrm{ml}$ and $63.3 \%$ mortality attained at $150 \mu \mathrm{g} / \mathrm{ml}$. On the $48 \mathrm{~h}$ exposure $56.6 \%$ mortality was observed at $50 \mu \mathrm{g} / \mathrm{ml} ; 66.6 \%$ at $100 \mu \mathrm{g} / \mathrm{ml}$ and $76.6 \%$ rate of mortality was observed at $150 \mathrm{\mu g} / \mathrm{ml}$. On the $3^{\text {rd }}$ day $93.3 \%$ mortality was recorded at $50 \mu \mathrm{g}$ and maximum rate of mortality of $100 \%$ attained on $100 \mu \mathrm{g}$ and $150 \mu \mathrm{g}$ (Fig. 7B).

The Sample C1 (72h) of quorum sensed extract showed $90 \%, 100 \%$ and $100 \%$ at $50 \mu \mathrm{g} / \mathrm{ml}, 100 \mu \mathrm{g} / \mathrm{ml}$ and $150 \mu \mathrm{g} / \mathrm{ml}$ on $24 \mathrm{~h}$ exposure. On $48 \mathrm{~h}$ and $72 \mathrm{~h}$ treatment maximum rate of mortality was recorded on $50 \mu \mathrm{g} / \mathrm{ml}, 100 \mu \mathrm{g} / \mathrm{ml}$ and $150 \mu \mathrm{g} / \mathrm{ml}$ (Fig. 7C). Among the samples significance was observed $\mathrm{p} \leq 0.01$ (Fig. 8). The $\mathrm{LC}_{50}$ value

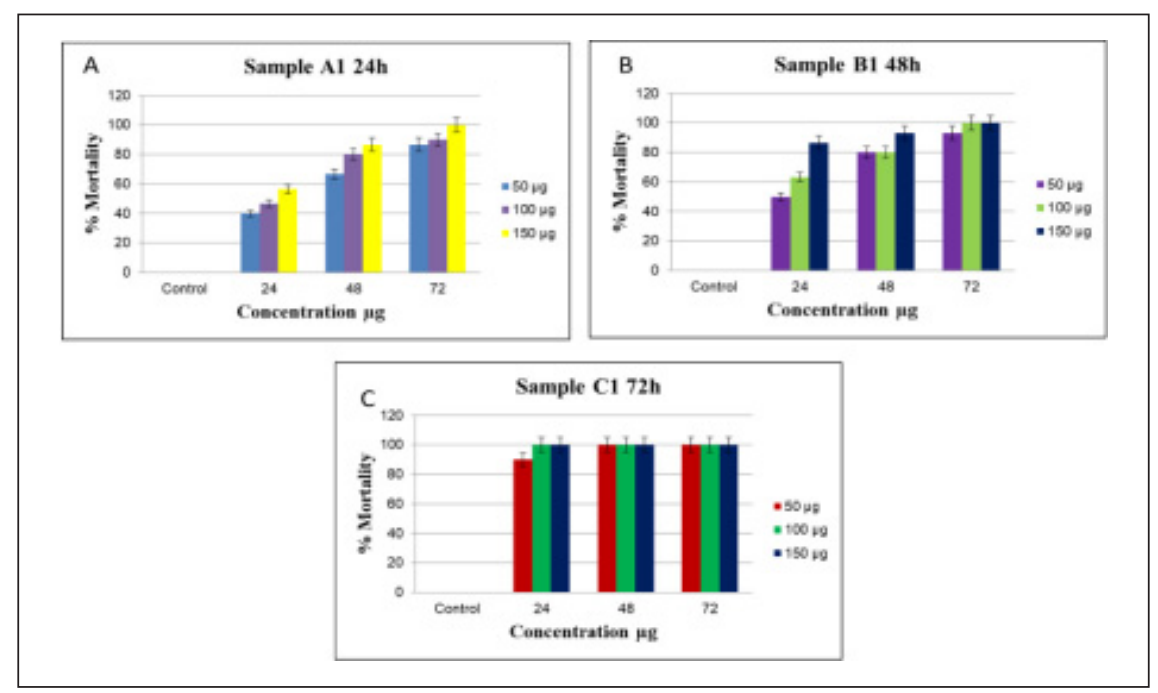

Figure 7a. Larvicidal Activity of Sample A1 24h; Fig. 7b Larvicidal Activity of Sample B1 48h; Fig. 7c Larvicidal Activity of Sample C1 72h against Aedes aegypti.

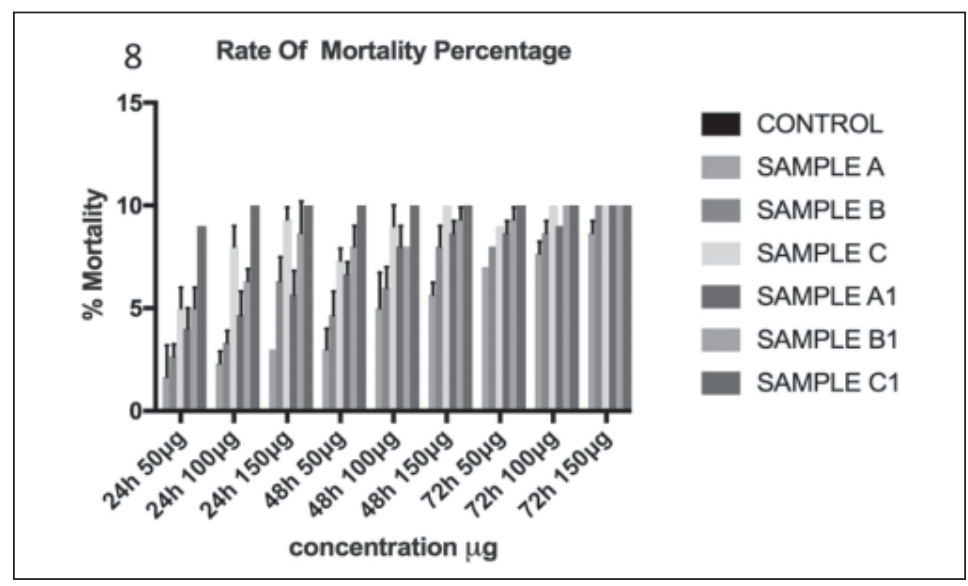

Figure 8. The larvicidal activity of the petroleum ether extracts against Aedes aegypti at different concentration ( $\mu \mathrm{g}$ ) for 24 to $72 \mathrm{~h}$ exposure. Significance was measured at $p \leq 0.01$. 


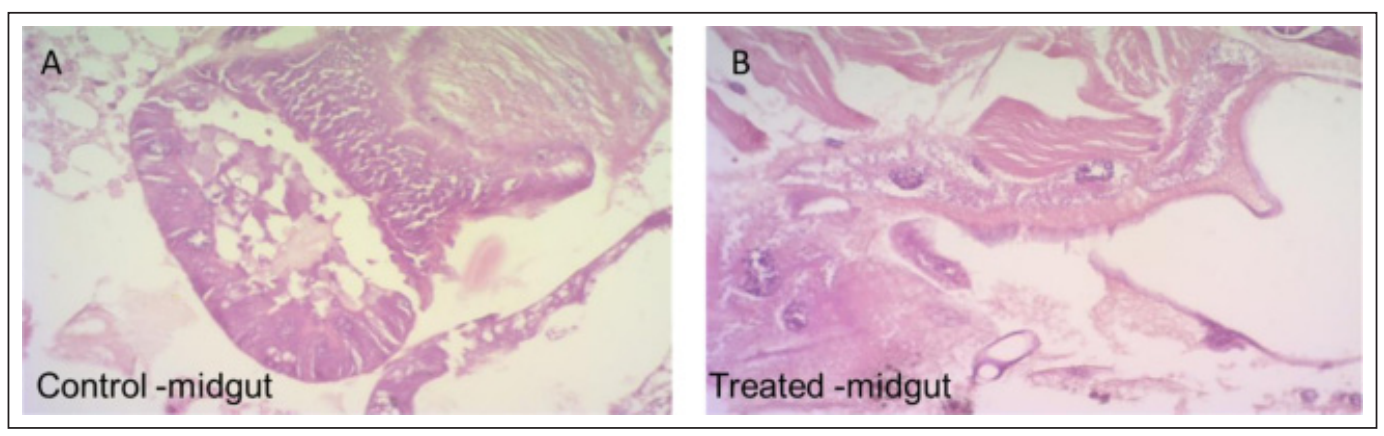

Figure 9a. Untreated Aedes aegypti larvae with intact midgut region; Fig. 9b Treated Aedes aegypti larvae with damaged midgut region.

were recorded as $2.38 \mu \mathrm{g} / \mathrm{ml}, 1.93 \mu \mathrm{g} / \mathrm{ml}$, $1.73 \mu \mathrm{g} / \mathrm{ml}$ for $50 \mu \mathrm{g}, 100 \mu \mathrm{g}$ and $150 \mu \mathrm{g}$ for Sample C and $1.77 \mu \mathrm{g} / \mathrm{ml}, 1.66 \mu \mathrm{g} / \mathrm{ml}, 1.66$ $\mu \mathrm{g} / \mathrm{ml}$ for $50 \mu \mathrm{g}, 100 \mu \mathrm{g}$ and $150 \mu \mathrm{g}$ for Sample C1.

\section{Histopathology}

Toxicity of larvicidal compounds from Xenorhabdus stockiae KUT6 in the midgut of the $4^{\text {th }}$ instar larvae of Aedes aegypti were studied by histopathology technique. Larvae treated with Xenorhabdus stockiae KUT6 secondary metabolites showed that the peritrophic membrane (PM), epithelial cells (EC) of the midgut have been damaged and there is also a leakage of the midgut contents (Figure 9B). Whereas in the control larvae midgut region is intact (Figure 9A).

\section{DISCUSSION}

In the present study Xenorhabdus stockiae KUT6 bacterial strain were isolated from agriculture soil field Kadayar, Kerala, India. The culture morphological characterization of the isolates were gram negative rod and highly motile. And on selective medium NBTA red core colonies surrounded by blue colour phase 1 colonies were developed. This assures the research similar to the Xenorhabdus species isolated from Nam Nao National Park, Thailand (Temsiri et al., 2018). The isolates were further confirmed through 16SrRNA sequencing. The phylogenetic tree analysis of 16SrRNA sequencing confirmed KUT6 strain as Xenorhabdus stockiae. The bacterial strain was cultured in Luria Broth and product yield were optimised through Quorum sensing using N-3oxododecanoyl homoserine lactone inducer for further experimental studies.

Identification of the toxic compound from the culture supernatant of Xenorhabdus stockiae KUT6 was done using petroleum ether extraction. Larvicidal activity against Aedes aegypti was carried out with the Sample A (24h), Sample B (48h) and Sample C (72h) culture supernatant and Sample A1 (24h), Sample B1 (48h) and Sample C1 (72h) induced QS culture supernatant extracts and mortality rate were observed from $24 \mathrm{~h}$ to $72 \mathrm{~h}$ exposure. Among the six samples the Sample C (72h) culture supernatant extract of Xenorhabdus stockiae KUT6 strain showed $100 \%$ mortality against the Aedes aegypti larvae at $100 \mu \mathrm{g}$ and $150 \mu \mathrm{g}$ on $48 \mathrm{~h}$ and $72 \mathrm{~h}$ exposure. Sample C1 (72h) optimised extract of Xenorhabdus stockiae KUT6 strain showed $100 \%$ mortality against the Aedes aegypti larvae at $100 \mu \mathrm{g}$ and $150 \mu \mathrm{g}$ on $24 \mathrm{~h}$ exposure. Petroleum ether at low concentration $(50 \mu \mathrm{g}-73 \%)$ is more toxic to the Aedes aegypti. The result of our study was appreciable as $50 \mu \mathrm{g} / \mathrm{ml}$ of petroleum ether extracts due to its virulence enhancement in quorum sensing recorded $100 \%$ mortality of Aedes aegypti at $24 \mathrm{~h}$ however, this result deviated with the earlier studies; on the solvent extracts of petroleum ether, chloroform and aqueous extracts obtained from Acalypha indica, Aerva Lanta, Boerhaavia diffusa, Commelina benghalensis, Gomphrena spp., Datura stramonium, Euphoria hurt, Cynodon spp., Lantana camera and Tridax procumbens. 
It was reported that the larvicidal activity was higher in petroleum extracts of the above plant with a higher concentration of $1000 \mu \mathrm{g} / \mathrm{ml}$ at $48 \mathrm{~h}$ exposure (Rajasekaran et al., 2012).

Based on our results the maximum mortality might be due to the absorbance of the toxic compounds through the cuticle of the larvae, as further development of the larvae were not observed (Brammacharry et al., 2012; Lalithambika et al., 2016). Untreated larvae in which the midgut region is intact. In the treated larvae after treatment shows that the peritrophic membrane (PM) and the epithelial cells (EC) of the midgut have been damaged and there is also a leakage of the midgut contents. Our result was in agreement with the result obtained by the research (Sugumar et al., 2014), it was noted that the Culex quinquefasciatus larvae when treated with eucalyptus oil nanoemulsions, showed that the damage of the peritrophic membrane and the epithelial cells of the midgut with leakage of the contents. Our results authenticated to be one of the best suitable biocontrol agent in containment of dengue fever. Further studies on the formulations will pave the way for control of Aedes aegypti which has developed resistance to DDT and synthetic pyrethroids reported recently (Kushwah et al., 2015; Jyotirmoy et al., 2006).

This research was effectuated to identify the maximal production of bioactive compounds from the culture supernatant. The production of compounds from Luria Broth and modified medium were recorded respectively. The larvicidal activity against $4^{\text {th }}$ instar larvae of Aedes aegypti was maximum in the modified medium; this may be due to increased production of compounds in the modified medium (Harshad et al., 2014).

The innovation of biological insecticides succeeds synthetic insecticides showing promising effects on various factors such as stability of the compound, stability of its activity against pathogens, low cost feasible effective compound production and product yield. Majority of biocontrol agents takes more than 3 days or weeks to thwart pests/pathogens; but nematode associated bacterial complexes shows its larvicidal activity within $24-72 \mathrm{~h}$ at maximal rate and minimal concentrations (Perez et al., 1990; Dilipkumar et al., 2017). Habitually Entomopathogenic nematodes functions as vector for transmitting its symbiotic bacteria to insect host; causing septicaemia within few days of infection. This parameter strengthens the strong specificity of our hypothesis against dengue vector Aedes aegypti.

\section{CONCLUSION}

In conclusion, the bacterial strains isolated from different agricultural soils were identified through 16SrRNA sequencing as Xenorhabdus stockiae KUT6 strain. Based on our bioassay, we defined the lethal larvicidal activity of Xenorhabdus stockiae KUT6 strain by examining the interaction against Aedes aegypti larvae within $24 \mathrm{~h}$ to $72 \mathrm{~h}$ treatment and is the best pathogen to the larvae. This indicates that Xenorhabdus stockiae KUT6 can be effective biocontol agent and the bioactive compounds should be further investigated for the application of the bacteria. The QS autoinducer induces the product yield but QS pathway studies will be carried out further.

Acknowledgements. This study was supported and funded by University Grant Commission - Maulana Azad National Fellowship (Grant Number - F1-17.1/201617/MANF-2015-17-KER-69816). We would like to thank Department of Biotechnology, Karunya Institute of Technology and Sciences. Many thanks are extended to Dr. Sankaranaryanan Department of Nematology, Sugar Cane Breeding Institute. We thank Poomalai D for his timely help; and also acknowledging our thanks to Mathew C Abraham, Susan Mathew, Blesson Mathew, Jeba Elis for all the supports.

\section{Conflicts of Interests}

The authors have declared no conflicts of interest. 


\section{REFERENCES}

Abott, W.S. (1925). A method of computing the effectiveness of an insecticide. Journal of Economic Entomology 18: 265-267.

Acosta, E.G., Castilla, V. \& Damonte, E.B. (2008). Functional entry of dengue virus into Aedes albopictus mosquito cells is dependent on clathrin-mediated endocytosis. Journal of General Virology 89: 474-484.

Alves, S.B., Alves, L.F.A., Lopes, R.B. \& Pereira, R.M. (2002). Potential of Some Metarhizium anisopliae Isolates for Control of Culex quinquefasciatus (Diptera, Culicidae). Journal of Applied Entomology 126: 504-509.

Bhardwaj, A.K. \& Mohanty, P. (2012). Bacterial Efflux Pumps Involved in Multidrug Resistance and their Inhibitors: Rejuvinating the Antimicrobial Chemotherapy. Rec. Patents on Anti-Infective Drug Discovery 7: 73-89.

Boszormenyi, E., Ersek, T. \& Fodor, A. (2009). Isolation and activity of Xenorhabdus antimicrobial compounds against the plant pathogens Erwinia amylovora and Phytophthora nicotianae. Journal of Applied Microbiology 107: 746-759.

Bowatte, G., Perera, P., Seneviratne, G. \& Meegaskumbura, S. (2013). Tadpoles as dengue mosquito (Aedes aegypti) egg predators. Biological Control 67: 469474.

Brammacharry, U. \& Paily, K. (2012). Chitinase like activity of metabolites of Pseudomonas fluorescens Migula on immature stages of the mosquito Culex quinquefasciatus (Diptera: Culicidae). African Journal of Microbiology Research 6: 2718-2726.

Chamaiporn, F., Thatcha, Y., Manawat, S. \& Paramaporn, M. (2017). Isolation and identification of Xenorhabdus and Photorhabdus bacteria associated with entomopathogenic nematodes and their larvicidal activity against Aedes aegypti. Parasites and Vectors 10: 440-450.

Chan, K., Atkinson, S. \& Mathew, K. (2011). Characterization of N-acylhomoserine lactone-degrading bacteria associated with the Zingiber officinale (ginger) rhizosphere: co-existence of quorum quenching and quorum sensing in Acinetobacter and Burkholderia. BMC Microbiology 11: 51-60.

Dilipkumar, A., Ramalingam, K.R., Govindhan, G. \& Paramasivam, D. (2017). Antibacterial activities of extracellular metabolites of symbiotic bacteria, Xenorhabdus and Photorhabdus isolated from entomopathogenic nematodes. International Biological and Biomedical Journal 3: 80-88.

Goh, K.N.S. \& Kumarapathy, S. (1985). Disease-bearing insects brought in by international aircraft into Singapore. Southeast Asian Journal. Tropical Medicine and Public Health 16: 49-53.

Guedes, E.A.C., De-Carvalho, C.M., RibeiroJunior, K.A.L. \& Lisboa, R.T.F. (2014). Larvicidal activity against Aedes aegypti and molluscicidal activity against Biomphalaria glabrata of Brazilian marine algae. Parasitolology 1: 1-6.

Harshad, L., Diby, P. \& Ji, H.K. (2014). N-Acyl Homoserine Lactone-Mediated Quorum Sensing with Special Reference to Use of Quorum Quenching Bacteria in Membrane Biofouling Control. BioMed Research International 10: 1-25.

Hinchliffe, S.J., Hares, M.C. \& Dowling, A.J. (2010). Insecticidal toxins from the Photorhabdus and Xenorhabdus bacteria. Open Toxinology Journal 3: 83-100.

Izabela, A., Rodenhuis-Zybert, J., Wilschut. \& Jolanda, M.S. (2010). Dengue virus life cycle: viral and host factors modulating Infectivity. Cellular and Molecular Life Sciences 67: 2773-2786.

Jyotirmoy, B., Jitendra, S., Mohan, C.J. \& Shubhendu, G. (2006). The cytotoxic fimbrial structural subunit of Xenorhabdus nematophila is a pore-forming toxin. Journal of Bacteriology 10: 87-113.

Kovendan, K., Murugan, K., Vincent, S. \& Kamalakannan, S. (2011). Larvicidal efficacy of Jatropha curcas and bacterial insecticide, Bacillus thuringiensis, against lymphatic filarial vector, Culex quinquefasciatus say (Diptera: Culicidae). Parasitology Research 109: 1251-1257. 
Kushwah, R.B.S., Mallick, P.K., Ravikumar, H. \& Dev, V. (2015). Status of DDT and pyrethroid resistance in Indian Aedes albopictus and absence of knockdown resistance (kdr) mutation. Journal of Vector Borne Diseases 52: 95-98.

Lade, H., Paul, D. \& Kweon, J.H. (2014). Isolation and molecular characterization of biofouling bacteria and profiling of quorum sensing signal molecules from membrane bioreactor activated sludge. International Journal of Molecular Sciences 15: 2255-2273.

Lalithambika, B. \& Vani, C. (2016). Pseudomonas aeruginosa KUN2, extracellular toxins - A potential source for the control of dengue vector. Journal of Vector Borne Diseases 53: 105-111.

Modis, Y., Ogata, S., Clements, D. \& Harrison, S.C. (2004). Structure of the dengue virus envelope protein after membrane fusion. Nature 427: 313-319.

Mustafa, M.S., Rastoqi, V., Jain, S. \& Gupta, V. (2015). Discovery of fifth stereo- type of dengue virus (DENV-5): A new public health dilemma in dengue control. Medical Journal Armed Forces India 71: 67-70.

National Vector Borne Disease Control Programme (2017-2018). Dengue fever Annual Report. 1-38.

Padmanabhan, V., Prabakaran, G., Paily, K.P. \& Balaraman, K. (2005). Toxicity of a mosquitocidal metabolite of Pseudomonas fluorescens on larvae and pupae of the house fly, Musca domestica. Indian Journal of Medical Research 121: 116119.

Park, Y. (2015). Entomopathogenic bacterium, Xenorhabdus nematophila and Photorhabdus luminescens, enhances Bacillus thuringiensis Cry4Ba toxicity against yellow fever mosquito, Aedes aegypti (Diptera: Culicidae). Journal of Asia-Pacific Entomology 18: 459-463.

Perez, C., Pauli, M. \& Bazerque, P. (1990). An antibiotic assay by the agar well diffusion method. Acta Biologiae et Medicinae Experimentalis 15: 113-115.
Rajasekaran, A. \& Geethapriya, D. (2012). Larvicidal activity of plant extracts on Aedes aegypti L. Asian Pacific Journal of Tropical Biomedicine 1: 1578-1582.

San-Blas, E., Cubillán, N. \& Guerra, M. (2017). Characterization of Xenorhabdus and Photorhabdus bacteria by Fourier transform mid-infrared spectroscopy with attenuated total reflection (FTIR/ ATR). Internaional Biological and Biomedical Journal 3: 20-27.

Setha, T., Chantha, N., Benjamin, S. \& Socheat, D. (2016). Bacterial larvicide, Bacillus thuringiensis israelensis strain AM 6552 water dispersible granule formulation impacts both dengue vector, Aedes aegypti (L.) population density and disease transmission in cambodia. PLoS Neglected Tropical Diseases 10: 1-15.

Sugumar, S., Clarke, S.K., Nirmala, M.J., Tyagi, B.K., Mukherjee, A. \& Chandrasekaran, N. (2014). Nanoemulsion of eucalyptus oil and its larvicidal activity against Culex quinquefasciatus. Bulletin of Entomological Research 104: 393-402.

Temsiri, Y., Paramaporn, M., Raxsina, P. \& Sarunporn, T. (2018). Identification of entomopathogenic nematodes and symbiotic bacteria from Nam Nao National Park in Thailand and larvicidal activity of symbiotic bacteria against Aedes aegypti and Aedes albopictus. Plos One 10: 1-19.

Van Der, S., Rust, H.M. \& Chen, J. (2008). Dissecting the cell entry pathway of dengue virus by single-particle tracking in living cells. Journal of Pathology 4: 250-256.

Vitta, A., Fukruksa, C., Yimthin, T. \& Deelue, K. (2017). Preliminary survey of entomopathogenic nematodes in upper northern Thailand. Southeast Asian Journal of Tropical Medicine and Public Health 48: 18-26.

WHO. (2016). www.who.int/mediacentre/ factsheets/fs117/en/

Yukiko, H. (2011). Dengue Vectors and their Spatial Distribution. Tropical Medicine and Health 39: 17-27. 